would like assurances that such exports did not contain specified bovine offals. "Until we know the exact nature of the exports to Thailand and other countries and what became of them, there exists the risk that they may have been given to cows and caused further contamination," he says, pointing out that many countries still lack surveillance networks for BSE.

For his part, A. Shimshony, Israel's director of Veterinary Services and Animal Health, is adamant that the imports into Israel consisted only of meat and bone meal derived from poultry. He points out that Israel banned the import of all mammalian meat and bone meal for feed use in 1990 .

Moreover, imports of meal derived from poultry were permitted only from mills certified to have never produced feeds of other animal origin, he says, in order to eliminate the risk of cross-contamination Indeed, Israel has a BSE surveillance network and has not detected any cases.

Johnston says that Israel's vigilance would be the exception rather than the rule, given that meat and bone meal is produced from cadavers, bones and other wastes from a variety of animals, and that it is consequently often difficult to distinguish what is and what is not derived from ruminants. Half a gram of infected meal is enough to kill a cow, he adds.

Indeed, Israel's action in 1990 seems almost clairvoyant. Most feed mills use the same equipment for producing all feeds. As a result, contaminated material intended for use in pig and poultry rations in the United Kingdom may have found its way into cattle feed. This is now acknowledged probably to account for most of the 27,100 cases of BSE in Britain since the introduction of the 1988 feed ban. But it was only in March this year that Britain recognized the risk and imposed a comprehensive ban on the feeding of mammalian-derived meat and bone meal to all farm animals.

While the recriminations over UK feed exports are likely to continue, the mad cow crisis has sent a shockwave through the feed industry that bodes well for the future safety of feed. The EU's council of agriculture ministers agreed in April that by the end of the year all rendering plants must convert to batch processing methods that use a temperature of $133{ }^{\circ} \mathrm{C}$ and pressure of 3 bars for at least 20 minutes. This means that "other epidemics of this nature cannot occur again", says Weimer.

Meanwhile, feedstuffs are not the only controversial exports from the United Kingdom in the BSE crisis. Many European countries are remaining remarkably discreet about the fact that they have also imported large numbers of breeding animals from BSE-infected herds in the United Kingdom, many of which could be incubating the disease. This means that although the Netherlands, for example, is listed as BSE-free, its disease status would probably be better described as unknown.

Declan Butler

\title{
Science agencies benefit as Congress eases up on cuts
}

Washington. The US Congress is quietly retreating from its previously stated objective of slashing the federal budget this year, leaving most science agencies in better shape than they were only a few months ago.

Bloodied by last year's prolonged budget conflict - from which it wrested billions of dollars of spending cuts but no political credit - the Republican-controlled Congress is now rushing to complete spending bills which will be more generous than expected, postponing tough action to balance the budget.

The House of Representatives, for example, is expected to complete each of the thirteen appropriations bills needed for the 1997 financial year, which begins 1 October, by early next month.

Next week, the Energy and Water appropriations subcommittee, chaired by John Myers (Republican, Indiana), will mark up a bill requiring cuts of around $\$ 200$ million. Earlier in the year, Myers was asked to make cuts of $\$ 1$ billion. His refusal to do so helped force an agreement last week between the House and the Senate which freed up an extra $\$ 4$ billion across the government.

The first bill of major importance to science funding was approved by the Veterans Affairs, Housing and Urban Development and independent agencies (VA-HUD) subcommittee two weeks ago. The subcommittee approved a budget for NASA of $\$ 13.6$ billion, compared with $\$ 13.8$ billion requested by President Bill Clinton. The $\$ 200$ million was cut from the Mission to Planet Earth programme. Science programmes at the Environmental Protection Agency would receive $\$ 540$ million, against $\$ 580$ million requested by Clinton.

Also in the VA-HUD bill, the National Science Foundation would get $\$ 3.25$ billion, against $\$ 3.325$ billion requested by Clinton. But the subcommittee was allocated an additional $\$ 350$ million under the new House-Senate agreement, and science lobbyists are working to get some of it for the National Science Foundation.

This week, the Labor, Health and Human Services and Education subcommittee was expected to mark up a bill that will contain more money for the National Institutes of Health $(\mathrm{NIH})$ than the $\$ 12.4$ billion requested by Clinton. The president's proposal would have allocated most of the NIH's 4 per cent budget increase to the construction of a new clinical centre (see Nature 380, 187; 1996). But John Porter (Republican, Illinois), the chairman of the subcommittee, is expected to secure a 6.5 per cent increase in NIH research grants, as well as money to start the new centre, in his bill.

Colin Macilwain

\section{European vote raises bioethics stakes}

Munich. The European Parliament is being asked to vote later this month on a resolution opposing all research on human embryos and on people who cannot give informed consent - referred to as "legally incapacitated persons" even though such research is currently allowed in several of the 15 member states of the European Union that the parliament represents.

Such a vote would have no legal status. But it would be intended to influence a draft bioethics convention being drawn up by the Council of Europe, a body representing 39 European countries, one of whose aims is to defend human rights. The new draft was approved last week by the council's executive, and will be voted on at its parliamentary assembly in September.

An initial draft of the convention was approved last year by this assembly by a narrow majority, on the understanding that it would undergo extensive rewording aimed at finding a consensus between countries such as Germany, which would like tough restrictions on research on humans and embryos, and France and Britain, which want more flexibility.

The new draft tightens up the wording, making explicit, for example, that the creation of human embryos for research purposes should be prohibited. But it accepts the principle that embryo research is otherwise allowable. It also allows research in principle on legally incapacitated persons.

Responding to an initiative of the European Parliament's research committee, headed by Christof Tannert, a member of Germany's Social Democrats, the legal affairs committee of the parliament last week approved a position paper requesting a long list of amendments to the draft.

Individual members of the Council of Europe will not be required to ratify the bioethics convention, even if the new draft is approved in September. But it will provide a form of indirect political pressure on countries such as Germany if it appears to have widespread approval.
Alison Abbott 